\title{
Solubility of all-trans retinoic acid in supercritical carbon dioxide
}

\author{
António B.S. Rosa, Sofia Marceneiro, Mara E.M. Braga, \\ Ana M.A. Dias*, Hermínio C. de Sousa* \\ CIEPQPF, Chemical Engineering Department, University of Coimbra, Rua Sílvio Lima, Pólo II-Pinhal de Marrocos, 3030-790 Coimbra, Portugal
}

\section{A R T I C L E I N F O}

\section{Article history:}

Received 11 November 2014

Received in revised form

31 December 2014

Accepted 31 December 2014

Available online 12 January 2015

\section{Keywords:}

All-trans retinoic acid

Solid solubility

Supercritical carbon dioxide

Particle size reduction

Density-based correlations

\begin{abstract}
A B S T R A C T
All-trans retinoic acid (ATRA) is a derivative of retinol (or vitamin A) presenting similar benefits but considerable lower adverse toxicity, mainly in cases of high or long-term therapeutic doses. ATRA showed to be effective in the treatment and/or chemoprevention of several epithelial and hematological malignancies and diverse dermatological and eye diseases however, its low solubility in aqueous media and photosensitivity hinder its wider usage by the conventional administration methods. Supercritical fluids technologies are being widely used to enhance the in vivo bioactivity of this type of drugs both by improving their dissolution rate (using particle size reduction processes) and/or by controlling their release into the media after incorporation into solid polymeric/inorganic matrices (using supercritical impregnation/foaming processes). In both cases the solubility of the drug in the supercritical fluid (usually $\mathrm{scCO}_{2}$ ) is required for process optimization purposes. Therefore, in this work the solubility of ATRA in $\mathrm{ScCO}_{2}$ was measured at different isotherms (308.2, 318.2 and $\left.328.2 \mathrm{~K}\right)$ and pressures that ranged from 10 up to $30 \mathrm{MPa}$ using a static analytical method. Solubility data were correlated using three commonly used density-based models, namely the Bartle, Chrastil and Méndez-Santiago-Teja models. The solubility of ATRA in $\mathrm{scCO}_{2}$ was found to be between $1.52 \times 10^{-6}$ and $1.84 \times 10^{-5}$ in terms of ATRA mole fraction and between $7.50 \times 10^{-3}$ and $1.07 \times 10^{-1}$ in terms of amount of solid solute per unit of volume of $\mathrm{scCO}_{2}$. Fairly good correlation agreement was obtained with all the applied models being the lowest deviations obtained with the Chrastil model. ATRA particles obtained after $\mathrm{scCO}_{2}$ processing (dissolution in $\mathrm{scCO}_{2}$ followed by re-precipitation) were characterized by scanning electron microscopy (SEM), X-ray diffraction (XRD), Fourier transform infrared (FTIR) and in vitro dissolution studies. The results showed that the processed particles maintained their chemical structure and presented enhanced dissolution in aqueous media (PBS: ethanol, 80:20, v/v) when compared with commercial (non-processed) ATRA.
\end{abstract}

(C) 2015 Elsevier B.V. All rights reserved.

\section{Introduction}

Retinoids are derivatives of retinol (or vitamin A) which play an important role in the regulation and control of many biological/physiological functions such as the induction of cellular proliferation, differentiation and apoptosis [1-5]. These derivatives have proved to present many of the vitamin A benefits but considerable lower adverse toxicity, mainly in cases of high or long-term therapeutic doses. Retinoic acid (Fig. 1) is derived from retinol and presents two biologically relevant isomers, namely the alltrans retinoic acid (ATRA) and the 9-cis-retinoic acid. In previously reported studies ATRA showed to be effective in the treatment and/or chemoprevention of several epithelial and hematological

\footnotetext{
* Corresponding authors. Tel.: +351 239798 700; fax: +351 239798703.

E-mail addresses: adias@eq.uc.pt (A.M.A. Dias), hsousa@eq.uc.pt, herminiosousa@gmail.com (H.C. de Sousa).
}

malignancies such as breast and lung cancer, promyelocytic leukemia, ovarian adenocarcinoma and human malignant gliomas [6-8] as well as diverse dermatological diseases such as acne, psoriasis and ichthyosis [3,9]. It has also proved to play a major role in maintaining the integrity of the cornea since it induces the proliferation and differentiation of corneal epithelial cells on both normal and diseased eye $[10,11]$.

Despite of the many therapeutic uses, ATRA delivery systems and formulations present several drawbacks which include photosensitivity, low solubility in aqueous media $(0.21 \mu \mathrm{M}$ at room temperature and $\mathrm{pH} 7.3$ [2]), local irritating reactions and uncomfortable side effects (e.g. headache, mucocutaneous dryness, hypertriglyceridermia, acute retinoid resistance or cancer relapse after a brief remission) which hinder its wider usage by the conventional administration methods [6,12]. Different formulations have been engineered to enhance ATRA bioavailability and favor its local sustained delivery by drug-loaded devices/scaffolds such as encapsulation in chitosan-based nanoparticles [6], biodegradable 


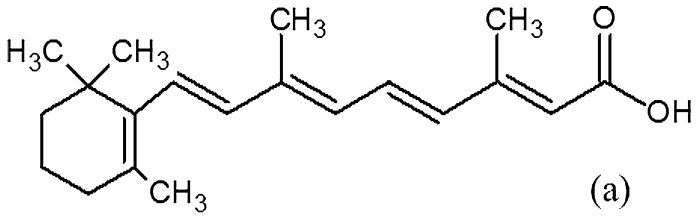<smiles>CC1=C(/C=C/C(C)=C/C=C/C(C)=C/CO)C(C)(C)CCC1</smiles>

Fig. 1. Chemical structure of all-trans retinoic acid (ATRA) (a) and retinol (b).

PLLA/PEG-PLLA blended microspheres [8], inorganically-coated all trans retinoic acid nanoparticles [10], polymeric micelles [12] and ophthalmic ointments [13]. Aiming eye treatment, care and/or protection ATRA (among other drugs) was also impregnated in contact lenses (by immersion of the lenses in drug(s) solution) [14].

Our research group has broad expertise on the impregnation of various drugs in different polymeric/inorganic matrices using supercritical fluid impregnation/deposition methodologies based on its recognized advantages over conventional drug incorporation methods, particularly when considering drugs with low solubility in aqueous media, and which mainly include the preparation of solvent free drug loaded devices, presenting patient-specific drug delivery profiles/rates obtained by the fine tune of mild process conditions [15-19]. Supercritical fluid processes such as rapid expansion of supercritical solutions (RESS), gas anti-solvent (GAS), supercritical anti-solvent (SAS) or supercritical assisted atomization (SAA) have also emerged as attractive methods for drug particle size reduction with clear enhancement of their dissolution rate and consequent bioavailability [20-25]. This is particularly important by knowing that more than $1 / 3$ of the drugs listed in the US Pharmacopoeia and more than $40 \%$ of newly discovered ones exhibit very low aqueous solubility $[20,21]$ thus requiring higher administration dosage and/or frequency in order to achieve therapeutic levels in target tissues/organs.

The optimization of both supercritical impregnation/deposition and particle size reduction processes requires the accurate knowledge of the equilibrium solubility of the drug to be impregnated and/or processed (micronized) in supercritical carbon dioxide $\left(\mathrm{scCO}_{2}\right)$. Therefore, and foreseeing the benefits of ATRA impregnation into contact lenses (or in other drug delivery devices), in this work the equilibrium solubility of all-trans retinoic acid in $\mathrm{ScCO}_{2}$ was experimentally measured at $308.2 \mathrm{~K}, 318.2 \mathrm{~K}$ and $328.2 \mathrm{~K}$, an over a pressure range from 9 up to $30 \mathrm{MPa}$ using a static analytical method coupled to a spectrophotometric quantification method. To the best of our knowledge, this is the first time that the equilibrium solubility data of ATRA in $\mathrm{scCO}_{2}$ is reported in the literature. Experimental solubility data measured for ATRA was further compared with data previously reported in the literature for retinol [26] in order to conclude about the influence of the chemical structure (in this specific case the substitution of the terminal hydroxyl functional group in retinol by the carboxyl functional group in retinoic acid) on the solubility of these compounds in $\mathrm{scCO}_{2}$. Experimental solubility data of both compounds were correlated with three density-based models (Chrastil, Bartle and Méndez-Santiago-Teja models) because they often deliver fairly accurate correlations at high simplicity which make them easy to apply. Finally, a preliminary essay to test the possibility of ATRA particle size reduction by using SCF processes was also attempted. The processed and nonprocessed particles were characterized for their morphology (by scanning electron microscopy), chemical structure and crystallinity (by Fourier transform infrared and X-ray diffraction) and in vitro dissolution rate.

\section{Materials and methods}

\subsection{Chemicals}

All-trans retinoic acid (CAS 302-79-4, purity $\geq 98 \%$ ) and naphthalene (CAS 91-20-3, purity $\geq 99.7 \%$ ) were purchased from
Sigma-Aldrich. Carbon dioxide (CAS 124-38-9, purity $>99.998 \%$, $\mathrm{v} / \mathrm{v}$ ) was supplied by Praxair, Spain and ethanol (CAS 64-17-5, purity $>99.9 \%, v / v$ ) was obtained by Scharlau, Spain. All the chemical reagents were used without further purification.

\subsection{Solubility determination}

\subsubsection{Apparatus and procedure}

Experimental equilibrium solubility data of ATRA in $\mathrm{scCO}_{2}$ were measured using a static analytical method and accordingly to the methodology previously described in the literature [27-35]. Briefly, it consists in a high pressure stainless steel equilibrium cell with sapphire windows connected to a six-port sampling valve, which is further connected to a known volume sampling loop followed by a glass trap (collector for the $\mathrm{scCO}_{2}$ solubilized solute with known volume) and a stainless steel balloon (with calibrated volume to quantify the solvent). The high pressure cell (HPC) and the sampling loop are immersed in a temperature-controlled water bath (controlled to within $\pm 0.1 \mathrm{~K}$ using a thermostat head from Thermo Haake, model DC30) while the glass trap and the stainless steel balloon are immersed in ice and in a room temperature water bath, respectively. The pressure is measured by a high-pressure transducer in the cell (up to $34.4 \pm 0.04 \mathrm{MPa}$ ) and in the calibrated balloon (up to $0.175 \pm 1.9 \times 10^{-4} \mathrm{MPa}$ ).

The HPC is loaded with an excess of ATRA $(\sim 100 \mathrm{mg})$ and a magnetic stirrer, and then placed into the thermostatic water bath over a magnetic stirrer plate to homogenize the ATRA $+\mathrm{scCO}_{2}$ mixture. At fixed experimental temperature, the high pressure cell is pressurized using a high-pressure liquid pump (Isco, model 260D) until the desired pressure is attained. After the system reaches equilibrium, the supercritical mixture is left for stirring for $3 \mathrm{~h}$, followed by a short period of time without stirring ( $\sim 15 \mathrm{~min})$ to allow stabilization. Then, a sample is taken from the HPC, through the six-port sampling valve into the sampling loop and further expanded into the glass trap and stainless steel balloon by depressurization. During the expansion step, the dissolved solid is precipitated into the glass trap. In order to recover all precipitated solid, ethanol was injected into the lines (sampling loop and expansion lines) and recollected into the glass trap. Fresh $\mathrm{CO}_{2}$ is then pumped through the lines for aditional cleaning and drying.

The amount of ATRA solubilized in $\mathrm{scCO}_{2}$ at each experimental condition was measured with a UV/vis spectophotometer (Jasco V650, Japan), measuring at $351 \mathrm{~nm}$, and using previously determined calibration. Since ATRA is a light sensitive compound, it was carefully stored and protected from the light to avoid degradation. The amount of $\mathrm{CO}_{2}$ in each sampling step was calculated using the Virial EOS (applied to pure $\mathrm{CO}_{2}$ ) as previously reported in the literature [27]. The overall uncertainty of the solubility measurements, taking into consideration the random uncertainties (statistical, associated to Beer-Lambert's calibration curve and to the average of the experimental solubility measurements) was found to be lower than $1.2 \times 10^{-6}$ (in terms of ATRA mole fraction, $y_{2}$ ). Each reported data point is the average of at least three replicate measurements with relative standard deviations (RSD) less than $4.6 \%$.

After the solubility measurements, the supercritical mixture $\left(\mathrm{scCO}_{2}+\mathrm{ATRA}\right)$ at $30 \mathrm{MPa}$ and $328.2 \mathrm{~K}$ was sudently depressurized 
to atmospheric pressure at $15 \mathrm{MPa} \mathrm{min}^{-1}$ and the obtained solid processed particles were collected for further analysis.

\subsection{Characterization methods}

Processed and non-processed ATRA particles were characterized by several methods, as described below, to infer about chemical and/or morphological changes after particles dissolution and precipitation in $\mathrm{ScCO}_{2}$.

\subsubsection{Scanning electron microscopy (SEM)}

The solid particles were observed using a scanning microscope (Jeol JSM-5310, Japan) with an operating voltage of $10 \mathrm{kV}$. The samples were sputter-coated with gold for $25 \mathrm{~s}(\sim 20 \mathrm{~nm}$ of film thickness).

\subsubsection{Fourier-transform infra-red spectroscopy (FTIR)}

The infrared spectra of the solid particles was obtained using a Fourier transform infrared spectrometer (Jasco FT/IR-4200, Japan) with a resolution of $4 \mathrm{~cm}^{-1}$ at 128 scans, in the spectral region from 4000 to $400 \mathrm{~cm}^{-1}$. The drug powders were mixed with potassium bromide $(\mathrm{KBr})$ at 1:100 and pressed into pellets using a hand press.

\subsubsection{X-ray diffraction (XRD)}

The chemical structure and crystallinity of the powder samples were analyzed by X-ray Diffraction (XRD) (Philips, X'Pert) operating in the Bragg-Brentano geometry with Co radiation $\left(\lambda \kappa_{\alpha 1}=0.178896 \mathrm{~nm}\right)$ and an accelerating voltage of $40 \mathrm{kV}$ at a current of $35 \mathrm{~mA}$. The diffraction patterns were obtained over $2 \theta$ values in the range from 4 to $35^{\circ}$ at a step size of $0.02^{\circ}$ and acquisition time of $2 \mathrm{~s}$.

\subsubsection{In vitro dissolution analysis}

ATRA dissolution measurements were performed in PBS: ethanol $(80: 20, v / v)$ using a spectrometer (Jasco, model V650, Japan) at $351 \mathrm{~nm}$. Processed and non-processed samples weighting $\sim 5 \mathrm{mg}$ were placed inside dialysis membranes (Spectra/Por Dialysis Membrane, MWCO 3500) and then immersed in $10 \mathrm{~mL}$ of the PBS:ethanol solution at $37^{\circ} \mathrm{C}$ and under stirring $(100 \mathrm{rpm})$ for $78 \mathrm{~h}$. At pre-determined time intervals, an aliquot of the dissolved drug solution was removed and analyzed, without renovation of the dissolution medium with fresh solvent. Drug concentration was calculated using previously determined concentration curves. All the experiments were carried out in triplicate.

\section{Correlation of experimental solubility data}

The experimental solubility data of ATRA in $\mathrm{scCO}_{2}$ measured in this work were correlated using three semi-empirical density-based models namely the Bartle, Chrastil and MéndezSantiago-Teja models.

\subsection{Density-based correlations}

\subsubsection{Bartle model}

Bartle and collaborators [36] proposed a correlation between the solubility of the solid in the supercritical fluid (expressed in terms of mole fraction, $y$, experimental pressure, $P$ [bar] and pure $\mathrm{CO}_{2}$ density, $\left.\rho\left[\mathrm{kg} \mathrm{m}^{-3}\right]\right)$ as defined in the following equation:

$\ln \left(\frac{y P}{P_{\text {ref }}}\right)=A+C\left(\rho-\rho_{\text {ref }}\right)$

$A=a+\frac{b}{T}$ where $P_{\text {ref }}$ is a standard reference pressure (set equal to 1 bar), $\rho_{\text {ref }}$ is a reference density (set equal to $700 \mathrm{~kg} \mathrm{~m}^{-3}$ ), T is the experimental temperature (K) and $a, b, A$ and $C$ are empirical constants obtained by fitting the solubility data points via multiple linear regression as previously described $[39,40,42]$. The parameter $b$ is related to the enthalpy of sublimation of the solid solute and is defined as $b=-\Delta H_{\text {sub }} / R$, where $R$ is the gas constant.

\subsubsection{Chrastil model}

The Chrastil model [37] correlates the solubility of a solid solute in the supercritical fluid with the density of the pure fluid and the absolute temperature, according to the following equation:

$\ln S=\kappa \ln \rho+\frac{\alpha}{T}+\beta$

where $S\left[\mathrm{~kg} \mathrm{~m}^{-3}\right]$ is the solubility of the solute in $\mathrm{scCO}_{2}, \rho\left[\mathrm{kg} \mathrm{m}^{-3}\right]$ is the density of pure $\mathrm{scCO}_{2}$ at the experimental temperature and pressure and $\kappa$ is the association number. The parameter $\alpha$ is defined as the sum of the vaporization and solvation enthalpies divided by the gas constant $(R)$, and $\beta$ is another constant related to the molecular weights of the solute and of the solvent. The model parameters $\alpha, \beta$ and $\kappa$ were obtained performing a multiple linear regression on the solubility data as previously described $[27,28,32]$.

\subsubsection{Méndez-Santiago and Teja model}

The Méndez-Santiago and Teja model [38] is based on the theory of diluted dilutions, that correlates the solubility of a solid solute ( $y$ mole fraction solubility) as a function of temperature and density of the supercritical fluid:

$T \ln (y P)=A^{\prime}+B^{\prime} \rho+C^{\prime} T$

where $A^{\prime}, B^{\prime}$ and $C^{\prime}$ are pressure and temperature independent constants, obtained from multiple linear regression of the experimental solubility data.

To evaluate the quality of the correlation, the error between the experimental $\left(y^{\exp }\right)$ and calculated $\left(y^{\mathrm{cal}}\right)$ solubility was estimated using different fitting statistic variables, namely $R$ square, average absolute relative deviation (AARD), standard error (SE) and maximum absolute relative error, in order to better access the correlation efficiency of the proposed density-based models. Models' parameters as well as the models' fitting errors are reported in Table 2.

\section{Results and discussion}

\subsection{Solubility measurements}

\subsubsection{Experimental results}

Prior to any experimental measurement with ATRA, the accuracy of the solubility measurements was established by measuring the solubility of naphthalene in $\mathrm{scCO}_{2}$ which is a reference system extensively studied in the literature. The solubility of naphthalene in $\mathrm{scCO}_{2}$ was measured at $308 \mathrm{~K}$ and in the pressure range from 10 to $30 \mathrm{MPa}$ and compared with data reported by different authors [39-44]. The results presented in Fig. 2 show that data measured in the present work is in good agreement with previously published data with an AARD of 5.7\%. The highest deviations $(13.7 \%$ and $13.4 \%$ ) were observed at lower pressure (10 MPa) and when comparing with data measured by Pauchon et al. [41] and Wagner et al. [43], respectively. These results, together with solubility data previously published for different solid solutes at different temperature, pressure and solubility ranges [27-35] and using the same apparatus and experimental procedures, confirm the accuracy of the measurements reported in the present work.

The solubility of ATRA in $\mathrm{scCO}_{2}$ was measured at three different temperatures $(308,318$ and $328 \mathrm{~K}$ ) and over a pressure 


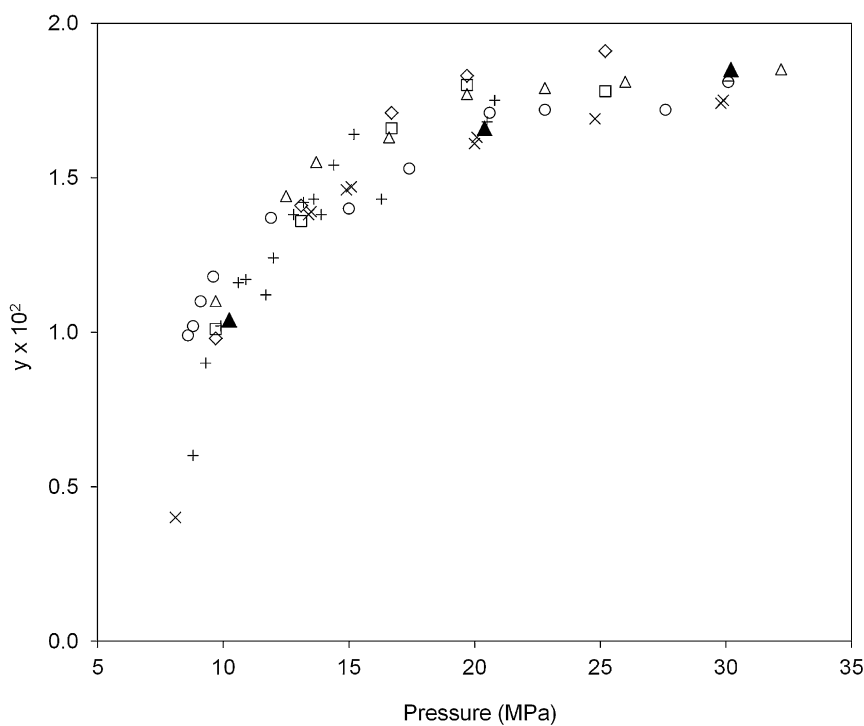

Fig. 2. Comparison between the solubility data of naphthalene in $\mathrm{scCO}_{2}$ measured in this work (expressed in mole fraction) with data previously reported in the literature: $(\diamond)$ McHugh and Paulaitis [44]; $(\square)$ Hourri et al. [40]; ( $\Delta)$ Pauchon et al. [41]; (○) Wagner et al. [43]; (+) Diefenbacher and Turk [39]; (x) Sauceau et al. [42]; (ム) This work.

Table 1

Experimental solubility of all-trans retinoic acid (ATRA) in supercritical carbon dioxide $\left(\mathrm{scCO}_{2}\right)$.

\begin{tabular}{lllll}
\hline$T(\mathrm{~K})$ & $P(\mathrm{MPa})$ & $\rho\left(\mathrm{kg} \mathrm{m}^{-3}\right)^{*}$ & $S \times 10^{2}\left(\mathrm{~kg} \mathrm{~m}^{-3}\right)$ & $y \times 10^{6}$ \\
\hline 308.2 & $10.6 \pm 0.5$ & 732.20 & $0.75 \pm 0.04$ & $1.52 \pm 0.08$ \\
& $15.3 \pm 0.6$ & 818.51 & $1.94 \pm 0.08$ & $3.47 \pm 0.14$ \\
& $20.4 \pm 0.2$ & 868.72 & $2.79 \pm 0.17$ & $4.70 \pm 0.28$ \\
& $25.2 \pm 0.2$ & 902.25 & $4.03 \pm 0.10$ & $6.54 \pm 0.16$ \\
318.2 & $30.1 \pm 0.3$ & 929.42 & $5.13 \pm 0.27$ & $8.08 \pm 0.42$ \\
& $10.3 \pm 0.3$ & 537.42 & $0.35 \pm 0.03$ & $0.96 \pm 0.68$ \\
& $15.4 \pm 0.5$ & 749.14 & $2.52 \pm 0.07$ & $4.93 \pm 0.14$ \\
& $20.5 \pm 0.3$ & 817.63 & $4.65 \pm 0.14$ & $8.33 \pm 0.26$ \\
& $25.3 \pm 0.4$ & 859.15 & $6.09 \pm 0.11$ & $10.38 \pm 0.18$ \\
& $31.2 \pm 0.3$ & 897.04 & $7.56 \pm 0.44$ & $12.42 \pm 0.72$ \\
& $10.2 \pm 0.1$ & 341.13 & $0.04 \pm 0.00$ & $0.19 \pm 0.02$ \\
& $15.3 \pm 0.3$ & 661.96 & $2.24 \pm 0.03$ & $4.96 \pm 0.07$ \\
& $20.7 \pm 0.5$ & 763.75 & $5.53 \pm 0.34$ & $10.61 \pm 0.64$ \\
& $25.4 \pm 0.5$ & 814.03 & $8.99 \pm 0.32$ & $16.18 \pm 0.57$ \\
& $30.3 \pm 1.0$ & 852.07 & $10.71 \pm 0.74$ & $18.41 \pm 1.27$ \\
\hline
\end{tabular}

* Data from NIST webbook (http://webbook.nist.gov/chemistry/).

range from 10 to $30 \mathrm{MPa}$. Experimental results are summarized in Table 1 where the solubility of ATRA in $\mathrm{scCO}_{2}$ is expressed in terms of mole fraction and amount of solid solute per unit of volume of $\mathrm{scCO}_{2}$. The presented values are an average of, at least, three experimental solubility measurements. The solubility ranged between $1.52 \times 10^{-6}$ and $1.84 \times 10^{-5}$ (in terms of mole fraction) and between $7.50 \times 10^{-3}$ and $1.07 \times 10^{-1}$ (in terms of amount of solid solute per unit of volume of $\mathrm{scCO}_{2}$ ). The average relative standard deviation (RSD) calculated for all the data points measured at the different experimental conditions was below 5\% which indicates good reproducibility and precision of the obtained data. As expected, and for each isotherm, the solubility of ATRA in $\mathrm{scCO}_{2}$ increased with pressure caused by the simultaneous increase in the density of the solvent (which increases with pressure at fixed temperature), that leads into a reduction of the intermolecular mean distance between solute and solvent molecules and consequently to an increase in the solubility of the solute at higher pressure (density). A crossover region was observed at $\sim 12-13 \mathrm{MPa}$ (Fig. 3 ) and it reflects the effect of the temperature on the equilibrium solubility which is simultaneously affected the solute vapor pressure and the solvent density. Below the crossover region the solvent

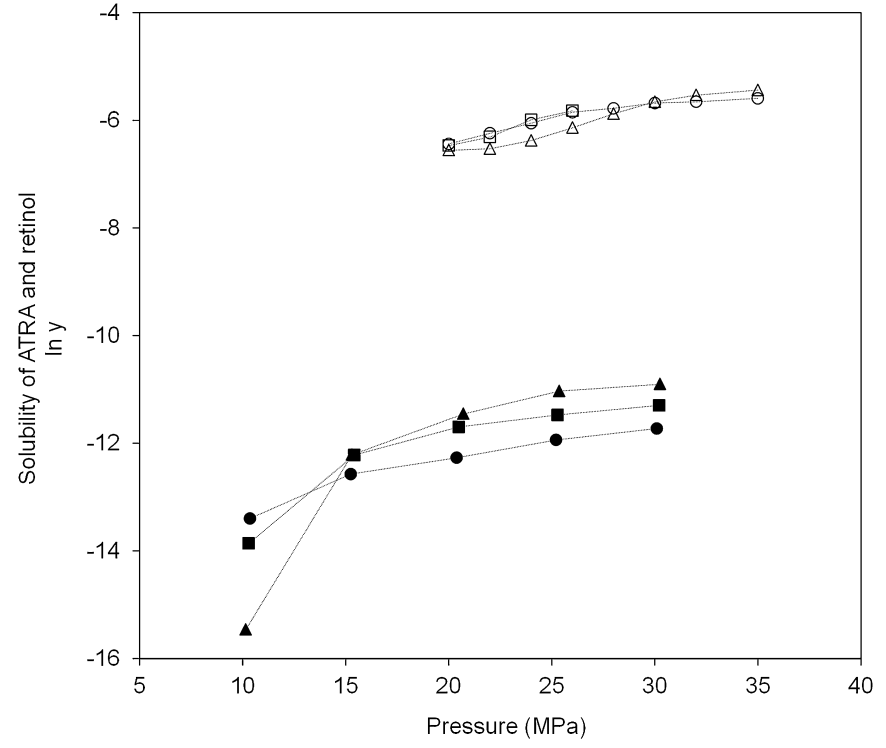

Fig. 3. Solubility data of all-trans retinoic acid (ATRA) and retinol in supercritical carbon dioxide $\left(\mathrm{scCO}_{2}\right)$ as a function of pressure and at different isotherms. Full symbols represent solubility data measured in this work for retinoic acid at (0) $308.2 \mathrm{~K}$, ( $\mathbf{\square}) 318.2 \mathrm{~K}$ and $(\boldsymbol{\Lambda}) 328.2 \mathrm{~K}$ while open symbols represent solubility data for retinol, taken from reference [26], at $(\bigcirc) 313.2 \mathrm{~K}$, ( $\square) 333.2 \mathrm{~K}$ and $(\Delta) 353.2 \mathrm{~K}$.

density (solvent power) effect is dominant so the solute is more soluble at low temperature and the solubility of ATRA decreases when temperature increases while above the crossover region the solute vapor pressure prevails over the solvent density and the solubility increases with temperature. This phenomenon is known as retrograde solubility behavior and was already reported in the literature for other solute-scCO $\mathrm{CH}_{2}$ systems [31,32,45-48].

The solubility data measured for ATRA was compared with that previously reported in the literature for retinol [26] to conclude about the influence of the substitution of the terminal carboxyl functional group in retinoic acid by the hydroxyl functional group in retinol on the solubility of each molecule in $\mathrm{scCO}_{2}$ (the chemical structure of both molecules is given in Fig. 1).

Even if considering that different experimental temperatures and measurement techniques were used in both works it can be seen in Fig. 3 that the substitution of the hydroxyl terminal group of retinol by the terminal carboxyl group of ATRA leads to a very significant decrease in the solubility of the acid in $\mathrm{scCO}_{2}$, which was found to be three orders of magnitude lower than that of the alcohol. A similar effect was observed by Iwai and coworkers [49] when comparing the solubility of stearyl alcohol with that of stearic acid in $\mathrm{scCO}_{2}$. This behavior is mostly due to the higher polarity of the carboxyl functional group which results from the presence of the strongly polarized carbonyl $(\mathrm{C}=\mathrm{O})$ and hydroxyl $(\mathrm{O}-\mathrm{H})$ groups. In this case the $\mathrm{O}-\mathrm{H}$ group is even more strongly polarized than the $\mathrm{O}-\mathrm{H}$ group of alcohols due to the presence of the adjacent carbonyl moiety [50]. The large number of strong dipoles allows carboxylic acids to interact trough favorable hydrogen bonding interactions, working as both $\mathrm{H}$-bond donors and acceptors, which favors the cohesion of the solid molecules and limits their solubility in $\mathrm{scCO}_{2}$. Moreover the molecular weight of ATRA $\left(300.44 \mathrm{~g} \mathrm{~mol}^{-1}\right)$ is also slightly higher than that of retinol $\left(286.45 \mathrm{~g} \mathrm{~mol}^{-1}\right)$ which also justifies the differences observed in the solubility of both compounds.

\subsubsection{Correlation results}

In this work, three density-based correlation methods, namely the Bartle, Chrastil and Méndez-Santiago-Teja models, were applied to correlate the experimental solubility data measured for ATRA as well as that previously reported in the literature for retinol. 


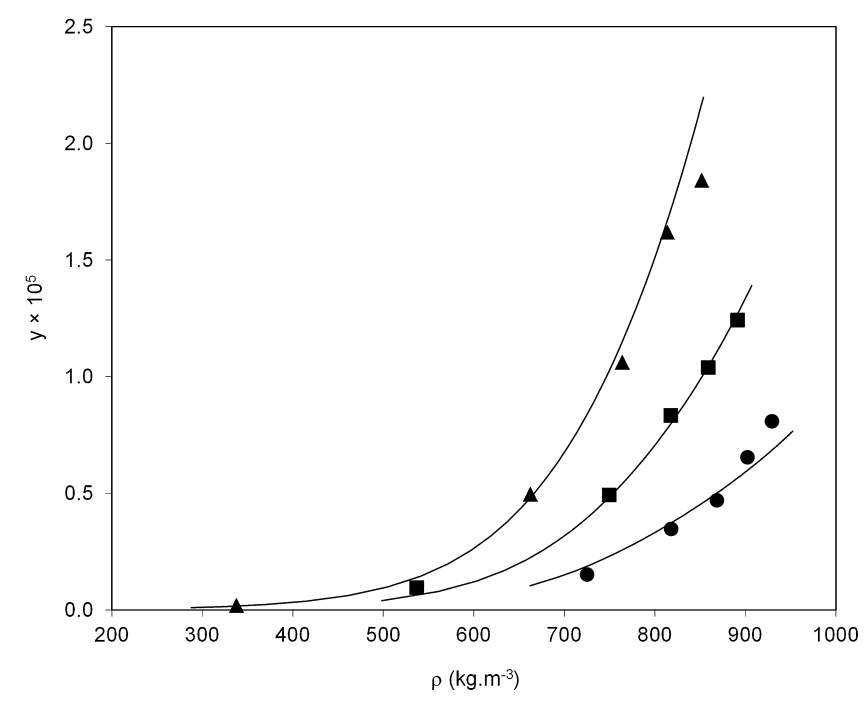

Fig.4. All-trans retinoic acid (ATRA) solubility $(y)$ as a function of pure $\mathrm{scCO}_{2}$ density. Symbols represent experimental data measured at: $308.2 \mathrm{~K}(\bullet)) ; 318.2 \mathrm{~K}(\boldsymbol{\square})$ and $328.2 \mathrm{~K}(\boldsymbol{\Delta})$ and the lines represent the correlation given by Bartle model.

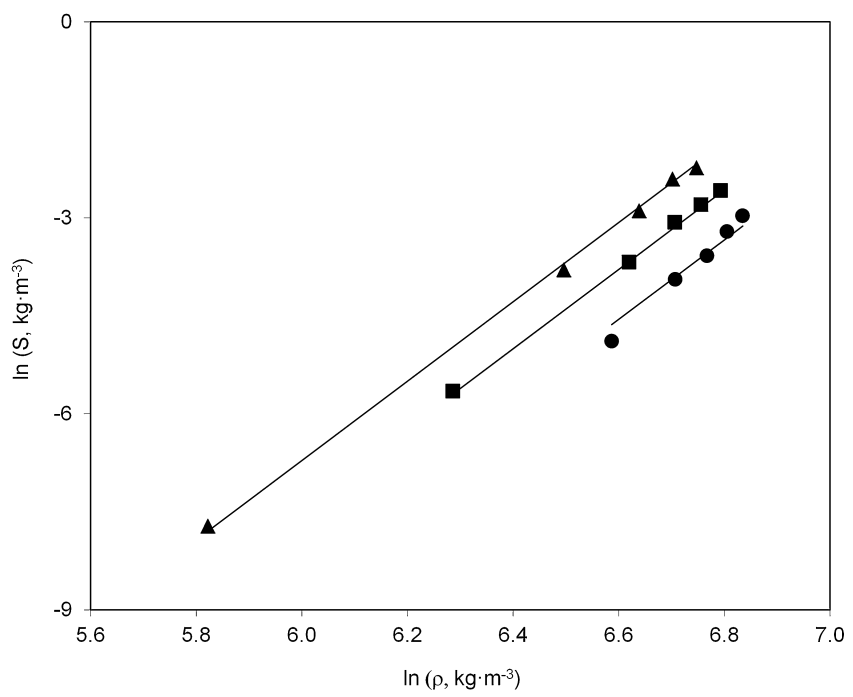

Fig. 5. Logarithmic relationship between the solubility of all-trans retinoic acid (ATRA) in $\mathrm{scCO}_{2}$ and the density of pure $\mathrm{scCO}_{2}$. Symbols represent experimental data measured at: $308.2 \mathrm{~K}(\bullet) ; 318.2 \mathrm{~K}(\boldsymbol{\bullet})$ and $328.2 \mathrm{~K}(\boldsymbol{\Delta})$ and the lines represent the correlation given by Chrastil model.

The correlation results obtained for ATRA are graphically represented in Figs. 4-6 and the fitting deviations obtained for both ATRA and retinol using the three density-based models are presented in Table 2. All together these results indicate that the three densitybased models were able to successfully correlate the experimental ATRA-scCO ${ }_{2}$ solubility data, with the lowest deviations observed for the Chrastil model, and to correctly describe both the dependence of the solubility with pressure (between 10 and $30 \mathrm{MPa}$ ) and temperature (between 308 and $328 \mathrm{~K}$ ).

The consistency of the solubility experimental data was also confirmed by the good correlation results obtained with the Méndez-Santiago-Teja model which showed very good convergence of all the solubility isotherms into a single straight line, even at solvent density where usually larger deviations from the fitted curves can be found. Finally, similar good correlation results were also obtained when using the Chrastil model to describe the experimental solubility data of retinol in $\mathrm{ScCO}_{2}$

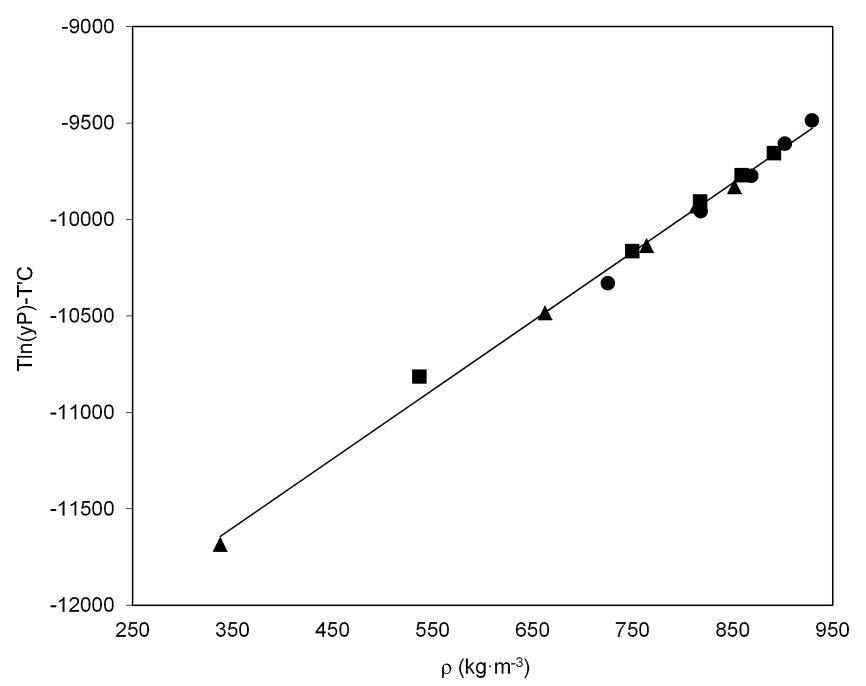

Fig. 6. Relationship between the solubility of all-trans retinoic acid (ATRA) in $\mathrm{scCO}_{2}$ and the density of $\mathrm{scCO}_{2}$. Symbols represent experimental data measured at: $308.2 \mathrm{~K}$ (•); $318.2 \mathrm{~K}(\mathbf{\square})$; $328.2 \mathrm{~K}(\boldsymbol{\Delta})$ and the lines represent the correlation given by MéndezSantiago-Teja model.

Table 2

Solubility correlation parameters obtained with the three employed density-based models for the studied temperatures (308.2, 318.2 and $328.2 \mathrm{~K}$ ).

\begin{tabular}{|c|c|c|}
\hline Chrastil model & ATRA & Retinol $^{*}$ \\
\hline$\kappa$ & $6.08 \pm 0.12$ & $6.08 \pm 0.44$ \\
\hline$\alpha(\mathrm{K})$ & $-7494.72 \pm 375.58$ & $-3079.24 \pm 339.77$ \\
\hline$\beta$ & $-20.33 \pm 1.11$ & $-28.69 \pm 2.12$ \\
\hline$\Delta H_{\text {total }}\left(\mathrm{kJ} \mathrm{mol}^{-1}\right)$ & -62.31 & -25.60 \\
\hline$R^{2}$ & 0.995 & 0.929 \\
\hline $\begin{array}{l}\text { Average absolute } \\
\text { relative deviation } \\
\text { (AARD) }\end{array}$ & 0.08 & 0.09 \\
\hline Standard error (SE) & 0.11 & 0.13 \\
\hline $\begin{array}{l}\text { Maximum absolute } \\
\text { relative error }\end{array}$ & 0.29 & 0.26 \\
\hline$N$ & 15 & 20 \\
\hline \multicolumn{3}{|l|}{ Bartle model } \\
\hline$a$ & $36.38 \pm 1.59$ & $23.90 \pm 0.66$ \\
\hline$b(\mathrm{~K})$ & $-10379.04 \pm 505.78$ & $-6161.42 \pm 220.02$ \\
\hline$C\left(\mathrm{~m}^{3} \mathrm{~kg}^{-1}\right)$ & $0.01 \pm 0.00034$ & $0.01 \pm 0.00077$ \\
\hline$\Delta H_{\text {sub }}\left(\mathrm{kJ} \mathrm{mol}^{-1}\right)$ & 86.29 & 51.23 \\
\hline$R^{2}$ & 0.970 & 0.977 \\
\hline $\begin{array}{l}\text { Average absolute } \\
\text { relative deviation } \\
\text { (AARD) }\end{array}$ & 0.10 & 0.11 \\
\hline Standard error (SE) & 0.16 & 0.16 \\
\hline $\begin{array}{l}\text { Maximum absolute } \\
\text { relative error }\end{array}$ & 0.34 & 0.40 \\
\hline$N$ & 15 & 20 \\
\hline \multicolumn{3}{|l|}{$\begin{array}{l}\text { Mendez- } \\
\text { Santiago-Teja } \\
\text { model }\end{array}$} \\
\hline$A(\mathrm{~K})$ & $-12846.90 \pm 553.87$ & $-8254.71 \pm 491.58$ \\
\hline$B\left(\mathrm{Km}^{3} \mathrm{~kg}^{-1}\right)$ & $3.58 \pm 0.09$ & $3.62 \pm 0.20$ \\
\hline$C$ & $24.76 \pm 1.64$ & $15.75 \pm 1.05$ \\
\hline$R^{2}$ & 0.993 & 0.953 \\
\hline $\begin{array}{l}\text { Average absolute } \\
\text { relative deviation } \\
\text { (AARD) }\end{array}$ & 0.09 & 0.09 \\
\hline Standard error (SE) & 46.49 & 41.41 \\
\hline $\begin{array}{l}\text { Maximum absolute } \\
\text { Relative error }\end{array}$ & 0.30 & 0.28 \\
\hline$N$ & 15 & 20 \\
\hline
\end{tabular}

$\operatorname{AARD}=(1 / N)\left(\sum_{i=1}^{N}\left(\left(\left|y_{i}^{\mathrm{cal}}-y_{i}^{\exp }\right|\right) / y_{i}^{\exp }\right)\right) ;$

$\mathrm{SE}=\sqrt{(1 /(N-\kappa-1)) \sum_{i=1}^{N}\left(y_{i}^{\mathrm{cal}}-y_{i}^{\exp }\right)^{2}}$, where $N$ is the number of solubility experimental data points and $\kappa$ is the number of independent variables in the model.

* Parameters correlated using experimental data previously reported by Johannsen and Brunner [26]. 

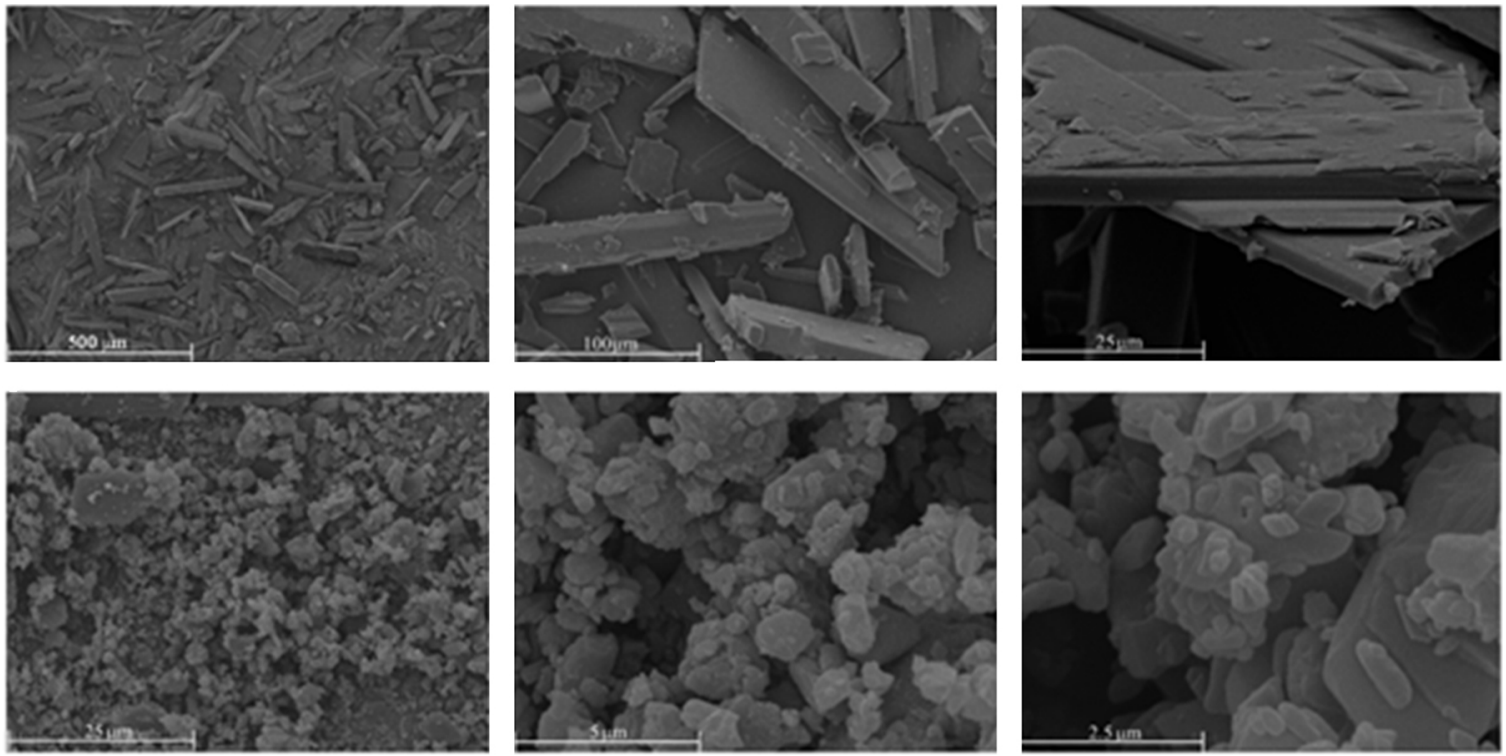

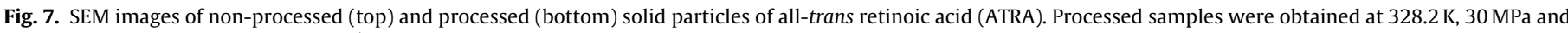
depressurization rate of $150 \mathrm{MPa} \mathrm{min}^{-1}$.

The values obtained from the Bartle model for the enthalpy of sublimation of ATRA $\left(86.3 \mathrm{~kJ} \mathrm{~mol}^{-1}\right)$ and retinol $\left(51.2 \mathrm{~kJ} \mathrm{~mol}^{-1}\right)$ confirm the presence of stronger solute-solute molecular interactions in the case of ATRA which justifies its lower solubility in $\mathrm{scCO}_{2}$, as discussed above. Furthermore, and considering the total enthalpy change ( $\left.\Delta H_{\text {total }}\right)$ calculated from the Chrastil model, it is possible to estimate the enthalpy of solvation $\left(\Delta H_{\text {solv }}\right)$ for both solutes as the difference between the total enthalpy and the vaporization enthalpy, which can be approximated to the solid's sublimation enthalpy calculated from the Bartle model. The calculated $\Delta H_{\text {solv }}$ were equal to $-148.6 \mathrm{~kJ} \mathrm{~mol}^{-1}$ for ATRA and $-76.8 \mathrm{~kJ} \mathrm{~mol}^{-1}$ for retinol indicating that, after sublimation, stronger intermolecular interactions can be found for the ATRA- $\mathrm{SCCO}_{2}$ system.

\subsection{Characterization of the ATRA $\mathrm{scCO}_{2}$ processed particles}

The morphology of ATRA particles before and after processing with $\mathrm{scCO}_{2}$ (at $30 \mathrm{MPa}$ and $328.2 \mathrm{~K}$ for $3 \mathrm{~h}$ and depressurized at $150 \mathrm{MPa} \mathrm{min}^{-1}$ ) was analyzed by SEM and is compared in Fig. 7. A clear reduction in the size of the solid particles was observed after ATRA dissolution in $\mathrm{scCO}_{2}$ and re-precipitation which is a good indication that supercritical fluid technologies can be used to micronize ATRA solid particles, with all the inherent advantages previously discussed, mainly the improved dissolution performance of micronized solid particles in biological fluids [20]. The effect of the particle size reduction on the dissolution profile of processed ATRA was compared with that of the commercial drug (non-processed) and the results are shown in Fig. 8. As can be seen, the processed particles present faster dissolution with a dissolution coefficient rate of $0.043 \mathrm{~min}^{-1}$ which is $~ 59 \%$ higher than that obtained for the commercial non-processed sample. The dissolution coefficient rate was calculated from the linear region of the dissolution profile (Fig. 8, inner figure) which was observed up to $8 \mathrm{~h}$ of dissolution. At this point (after $8 \mathrm{~h}$ ) the concentration of processed ATRA in the medium is about $40 \%$ higher than that of the non-processed sample (the percentage of ATRA dissolved after $8 \mathrm{~h}$ was equal to $25 \%$ and $35 \%$ for the processed and non-processed samples, respectively). Notice that these results can be, in principle, improved if processing variables (pressure, temperature, contact time, depressurization rate, nozzle

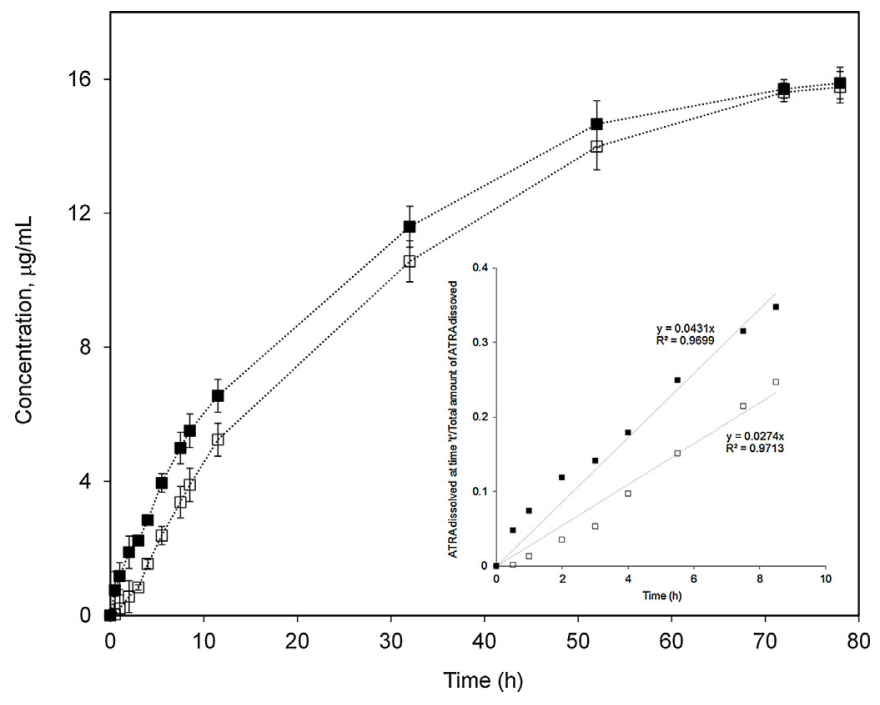

Fig. 8. Dissolution profiles of non-processed $(\square)$ and $\mathrm{scCO}_{2}$ processed ( $\left.\boldsymbol{\square}\right)$ all-trans retinoic acid (ATRA)

geometry) are optimized; however this study was outside the scope of this work. Similar results have been reported in the literature for different drugs and in all cases the dissolution rate were significantly enhanced after supercritical processing [20,48,51]. Finally, FTIR and XRD analysis were performed to evaluate possible chemical and/or structural changes/rearrangements of the ATRA particles after $\mathrm{scCO}_{2}$ processing. The results shown in Fig. 9a (FTIR data) and 9b (XRD data) do not show any appreciable difference with respect to ATRA's crystallinity or structure which maintained the original monoclinic phase [52] without the formation of any new phases. These results indicate that $\mathrm{scCO}_{2}$ processing can be used to enhance the dissolution performance of ATRA without affecting its chemical structure and therefore guarantying that its bioactivity and natural function is not altered which are crucial factors to be considered for the development of novel drug delivery controlled systems. 


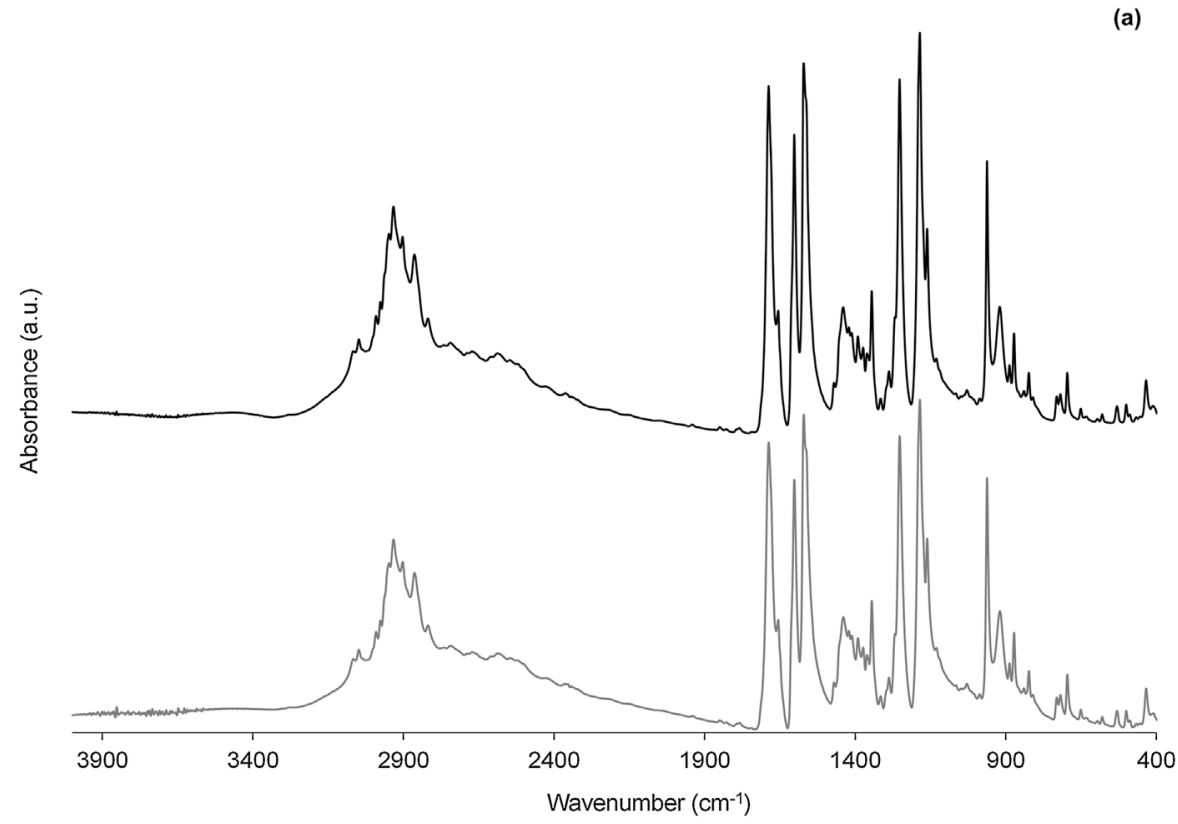

(b)

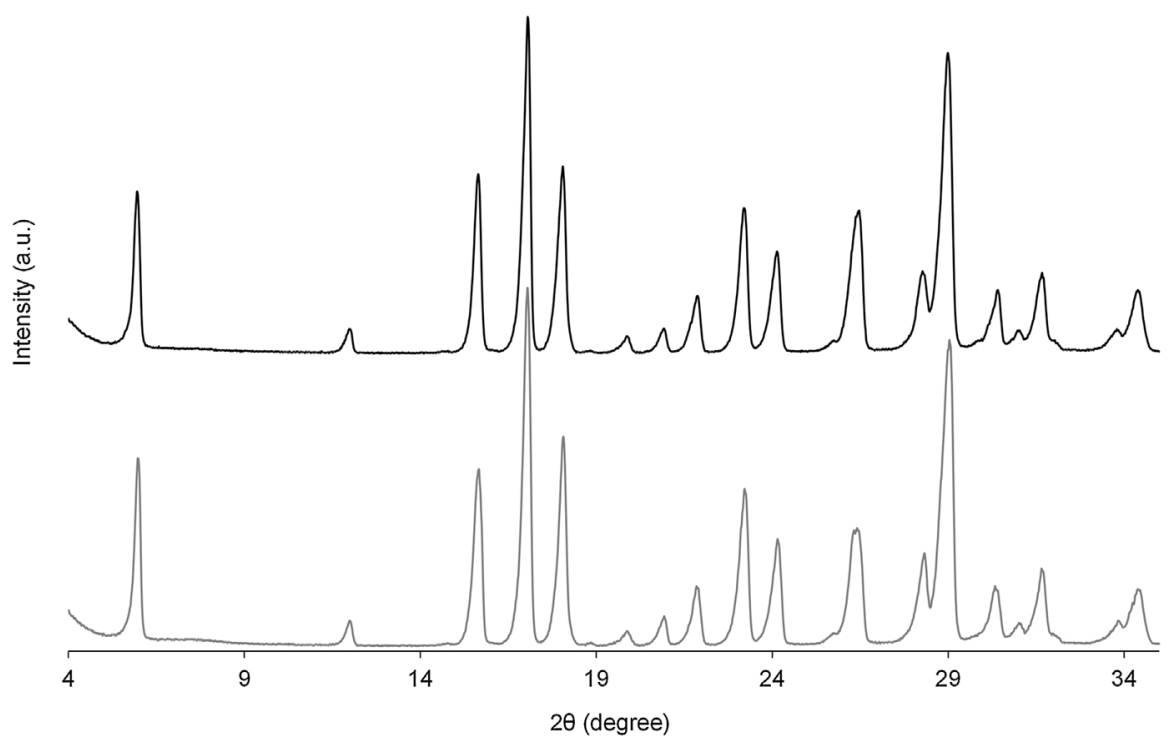

Fig. 9. Characterization of non-processed (light grey line) and processed (black line) all-trans retinoic acid (ATRA): (a) FTIR spectra, (b) XRD patterns.

\section{Conclusions}

In this work, the equilibrium solubility of ATRA in $\mathrm{scCO}_{2}$ was measured at three different temperatures (308, 318 and $328 \mathrm{~K}$ ) and at pressure varying from 10 to $30 \mathrm{MPa}$ using a static analytic method. The accuracy of the experimental equipment was evaluated by comparing solubility data measured for naphthalene with data previously reported in the literature and measured by several authors. Good agreement was found between data measured in this work and literature, with an AARD of $5.7 \%$. As expected, the solubility of ATRA in $\mathrm{ScCO}_{2}$ increased with pressure for all isotherms. Furthermore, a pressure crossover region was identified between $12-13 \mathrm{MPa}$. The solubility of ATRA in $\mathrm{scCO}_{2}$ ranged between $1.52 \times 10^{-6}$ and $1.84 \times 10^{-5}$ (in terms of mole fraction) which is three orders of magnitude lower than that previously reported in the literature for retinol. This result was mainly justified by the stronger intensity of the chemical interactions that can be established between the carboxylic groups of ATRA, when compared to the hydroxyl groups of retinol, and which favors the cohesion of the solid molecules and limits their solubility in $\mathrm{scCO}_{2}$. Experimental solubility data of ATRA and retinol (data taken from the literature) were correlated using three commonly used density based models (Bartle, Chrastil and Méndez-Santiago-Teja) and satisfactory correlation results were found with an AARD lower than $10 \%$ in both cases. Finally it was shown that $\mathrm{scCO}_{2}$ processing does not alter the chemical structure of ATRA and significantly improved its dissolution rate in aqueous media as confirmed by an increase of almost $60 \%$ in the dissolution coefficient rate (measured up to $8 \mathrm{~h}$ of dissolution) when compared with the commercial non-processed sample. All 
together these results indicate that supercritical fluid processes can be advantageously used to develop ATRA delivery biomedical devices or formulations with improved drug bioavailability and controlled release rates without affecting ATRA's chemical structure.

\section{Acknowledgements}

This work was supported by FCT-MEC (Portugal) under contracts PEst-C/EME/UI0285/2013 and Investigador FCT IF/00455/2013, and by Programa Ciência 2008 (Portugal), FEDER (Portugal) and COMPETE (Portugal).

\section{References}

[1] I. Fernández, D.M. Tiago, V. Laizé, M.L. Cancela, E. Gisbert, Retinoic acid differentially affects in vitro proliferation, differentiation and mineralization of two fish bone-derived cell lines: different gene expression of nuclear receptors and ECM proteins, J. Steroid Biochemistry and Molecular Biology 140 (2014) 34-43.

[2] E.Z. Szuts, F.I. Harosi, Solubility of retinoids in water, Archives of Biochemistry and Biophysics 287 (1991) 297-304.

[3] P. Purushottamachar, J.B. Patel, O.O. Clement, V.C.O. Njar, First chemical featurebased pharmacophore modeling of potent retinoidal retinoic acid metabolism blocking agents (RAMBAs): identification of novel RAMBA scaffolds, European J. Medicinal Chemistry 47 (2012) 412-423.

[4] G. Duester, Retinoic synthesis and signaling during early organogenesis, Cell 134 (2008) 921-931.

[5] M. Rhinn, P. Dollé, Retinoic acid signalling during development, Development 139 (2012) 843-858.

[6] K.-D. Chung, Y.-I. Jeong, C.-W. Chung, D.H. Kim, D.W. Kang, Anti-tumor activity of all-trans retinoic acid-incorporated glycol chitosan nanoparticles against HuCC-T1 human cholangiocarcinoma cells, International J. Pharmaceuticals 422 (2012) 454-461.

[7] R.-J. Li, X. Ying, Y. Zhang, R.-J. Ju, X.-X. Wang, H.-J. Yao, Y. Men, W. Tian, Y. Yu, L. Zhang, R.-J. Huang, W.-L. Lu, All-trans retinoic acid stealth liposomes prevent the relapse of breast cancer arising from the cancer stem cells, J. Controlled Release 149 (2011) 281-291.

[8] Y. Choi, S.Y. Kim, S.H. Kim, K.-S. Lee, C. Kim, Y. Byun, Long-term delivery of alltrans-retinoic acid using biodegradable PLLA/PEG-PLLA blended microspheres, International J. Pharmaceuticals 215 (2001) 67-81.

[9] V.C.O. Njar, L. Gediya, P. Purushottamachar, P. Chopra, T.S. Vasaitis, A. Khandelwal, A. Mehta, C. Huynh, A. Belosay, J. Patel, Retinoic acid metabolism blocking agents (RAMBAs) for treatment of cancer and dermatological diseases, Bioorganic \& Medicinal Chemistry 14 (2006) 4323-4340.

[10] M. Hattori, K. Shimizu, K. Katsumura, Y. Sano, H. Oku, K. Matsumoto, Y. Yamaguchi, T. Ikeda, Effects of all-trans retinoic acid nanoparticles on corneal epithelial wound healing, Graefe's Archive for Clinical and Experimental Ophthalmology 250 (2012) 557-563.

[11] J. Rong, S. Liu, Effect of all-trans retinoic acid on the barrier function in human retinal pigment epithelial cells, Biochemical and Biophysical Research Communications 407 (2011) 605-609.

[12] Y.-I. Jeong, S.-H. Kim, T.-Y. Jung, I.-Y. Kim, S.-S. Kang, Y.-H. Jin, H.-H. Ryu, H.-S. Sun, S. Jin, K.-K. Kim, K.-Y. Ahn, S. Jung, Polyion complex micelles composed of all-trans retinoic acid and poly(ethylene glycol)-grafted-chitosan, J. Pharmaceutical Sciences 95 (2006) 2348-2360.

[13] S.C.G. Tseng, A.E. Maumenee, W.J. Stark, I.H. Maumenee, A.D. Jensen, W.R. Green, K.R. Kenyon, Topical retinoid treatment for various dry-eye disorders, Ophthalmology 92 (1985) 717-727.

[14] L.J. Wagenaar, Procedure and composition of treatment and/or care of the eye,Patent CA2434242 A1, USA, 2009.

[15] F. Yañez, L. Martikainen, M.E.M. Braga, C. Alvarez-Lorenzo, A. Concheiro, C.M.M. Duarte, M.H. Gil, H.C. de Sousa, Supercritical fluid-assisted preparation of imprinted contact lenses for drug delivery, Acta Biomaterialia 7 (2011) 1019-1030.

[16] M.E.M. Braga, V.P. Costa, M.J.T. Pereira, P.T. Fiadeiro, A.P.A.R. Gomes, C.M.M. Duarte, H.C. de Sousa, Effects of operational conditions on the supercritical solvent impregnation of acetazolamide in balafilcon A commercial contact lenses, International J. Pharmaceuticals 420 (2011) 231-243.

[17] V.P. Costa, M.E.M. Braga, C.M.M. Duarte, C. Alvarez-Lorenzo, A. Concheiro, M.H. Gil, H.C. de Sousa, Anti-glaucoma drug-loaded contact lenses prepared using supercritical solvent impregnation, J. Supercritical Fluids 53 (2010) $165-173$.

[18] V.P. Costa, M.E.M. Braga, J.P. Guerra, A.R.C. Duarte, C.M.M. Duarte, E.O.B. Leite, M.H. Gil, H.C. de Sousa, Development of therapeutic contact lenses using a supercritical solvent impregnation method, J. Supercritical Fluids 52 (2010) 306-316.

[19] C. González-Chomón, M.E.M. Braga, H.C. de Sousa, A. Concheiro, C. AlvarezLorenzo, Antifouling foldable acrylic IOLs loaded with norfloxacin by aqueous soaking and by supercritical carbon dioxide technology, European J. Pharmaceutics and Biopharmaceutics 82 (2012) 383-391.
[20] M. Perrut, J. Jung, F. Leboeuf, Enhancement of dissolution rate of poorly-soluble active ingredients by supercritical fluid process, Part I: Micronization of neat particles, International J. Pharmaceuticals 288 (2005) 3-10.

[21] T. Yasuji, H. Takeuchi, Y. Kawashima, Particle design of poorly-soluble drug substances using supercritical fluid technologies, Advanced Drug Delivery Reviews 60 (2008) 388-398.

[22] N. Yildiz, S. Tuna, O. Doker, A. Calimli, Micronization of salicylic acid and taxol (paclitaxel) by rapid expansion of supercritical fluids, The J. Supercritical Fluids 41 (2007) 440-451.

[23] A. Martín, M.J. Cocero, Micronization processes with supercritical fluids: fundamentals and mechanisms, Advanced Drug Delivery Reviews 60 (2008) 339-350.

[24] E. Reverchon, G.D. Porta, Micronization of antibiotics by supercritical assisted atomization, J. Supercritical Fluids 26 (2003) 243-252.

[25] I. Pascali, R. Bettini, F. Giordano, Solid-state chemistry and particle engineering with supercritical fluids in pharmaceutics, European J. Pharmaceutical Sciences 27 (2006) 299-310

[26] M. Johannsen, G. Brunner, Solubilities of fat-soluble vitamins A, D, E, and K in supercritical carbon dioxide, J. Chemical and Engineering Data 42 (1997) $106-111$.

[27] P. Coimbra, M.H. Gil, C.M.M. Duarte, B.M. Heron, H.C. de Sousa, Solubility of a spiroindolinonaphthoxazine photochromic dye in supercritical carbon dioxide: experimental determination and correlation, Fluid Phase Equilibria 238 (2005) $120-128$.

[28] P. Coimbra, C.M.M. Duarte, H.C. de Sousa, Cubic equation-of-state correlation of the solubility of some anti-inflamatory drugs in supercritical carbon dioxide, Fluid Phase Equilibria 239 (2006) 188-199.

[29] P. Coimbra, D. Fernandes, M.H. Gil, H.C. de Sousa, Solubility of diflunisal in supercritical carbon dioxide, J. Chemical and Engineering Data 53 (2008) 1990-1995.

[30] P. Coimbra, D. Fernandes, P. Ferreira, M.H. Gil, H.C. de Sousa, Solubility of Irgacure 2959 photoinitiator in supercritical carbon dioxide: experimental determination and correlation, The J. Supercritical Fluids 45 (2008) $272-281$.

[31] S. Marceneiro, P. Coimbra, M.E.M. Braga, A.M.A. Dias, H.C. de Sousa, Measurement and correlation of the solubility of Juglone in supercritical carbon dioxide, Fluid Phase Equilibria 311 (2011) 1-8.

[32] S. Marceneiro, M.E.M. Braga, A.M.A. Dias, H.C. de Sousa, Measurement and correlation of 1,4-naphthoquinone and of plumbagin solubilities in supercritical carbon dioxide, J. Chemical and Engineering Data 56 (2011) 4173-4182.

[33] R. Chim, S. Marceneiro, M.E.M. Braga, A.M.A. Dias, H.C. de Sousa, Solubility of norfloxacin and ofloxacin in supercritical carbon dioxide, Fluid Phase Equilibria 331 (2012) 6-11.

[34] R.B. Chim, M.B.C. de Matos, M.E.M. Braga, A.M.A. Dias, H.C. de Sousa, Solubility of dexamethasone in supercritical carbon dioxide, J. Chemical and Engineering Data 57 (2012) 3756-3760.

[35] H.C. de Sousa, M.S. Costa, P. Coimbra, A.A. Matias, C.M.M. Duarte, Experimental determination and correlation of meloxicam sodium salt solubility, J. Supercritical Fluids 63 (2012) 40-45.

[36] K.D. Bartle, A.A. Clifford, S.A. Jafar, G.F. Shilstone, Solubilities of solids and liquids of low volatility in supercritical carbon dioxide, J. Physical and Chemical Reference Data 20 (1991) 713-756.

[37] J. Chrastil, Solubility of solids and liquids in supercritical gases, J. Physical Chemistry 86 (1982) 3016-3021.

[38] J. Méndez-Santiago, A.S. Teja, The solubility of solids in supercritical fluids, Fluid Phase Equilibria 158 (1999) 501-510.

[39] A. Diefenbacher, M. Turk, Phase equilibria of organic solid solutes and supercritical fluids with respect to the RESS process, J. Supercritical Fluids 22 (2002) 175-184.

[40] A. Hourri, J.M. St-Arnaud, T.K. Bose, Solubility of solids in supercritical fluids from the measurements of the dielectric constant: application to $\mathrm{CO}_{2}$-naphtalene, Review of Scientific Instruments 69 (1998) 2732-2737.

[41] V. Pauchon, Z. Cissé, M. Chavret, J. Jose, A new apparatus for the dynamic determination of solid compounds solubility in supercritical carbon dioxide. Solubility determination of triphenylmethane, J. Supercritical Fluids 32 (2004) 115-121.

[42] M. Sauceau, J. Fages, J.-J. Letourneau, D. Richon, A novel apparatus for accurate measurements of solid solubilities in supercritical phases, Industrial and Engineering Chemistry Research 39 (2000) 4609-4614.

[43] K.-D. Wagner, N. Dahmen, E. Dinjus, Solubility of triphenysphosphine, tris( $p$-flourophenyl)phosphine, tris(pentafluoropheny)phosphine, and tris( $p$ trisfluoromethylphenyl)phosphine in liquid and supercritical carbon dioxide, J. Chemical Engineering Data 45 (2000) 672-677.

[44] M. McHugh, M.E. Paulaitis, Solid solubilities of naphtalene and biphenyl in supercritical carbon dioxide, J. Chemical Engineering Data 25 (1980) 326-329.

[45] A.R.C. Duarte, S. Santiago, H.C. de Sousa, A.R.C. Duarte, Solubility of acetazolamide in supercritical carbon dioxide in the presence of ethanol as a cosolvent, J. Chemical and Engineering Data 50 (2005) 216-220.

[46] J. Jin, Y. Wang, H. Wu, J. Li, Z. Zhang, Equilibrium solubilities of ammonium benzoate, benzamide and their mixture in supercritical carbon dioxide, Fluid Phase Equilibria 334 (2012) 152-156.

[47] M. Khamda, M.H. Hosseini, M. Rezaee, Measurement and correlation solubility of cefixime trihydrate and oxymetholone in supercritical carbon dioxide, J. Supercritical Fluids 73 (2013) 130-137. 
[48] Z. Huang, Y.-H. Gua, H. Miao, L--J. Teng, Solubility of progesterone in supercritical carbon dioxide and its micronization through RESS, Powder Technology 258 (2014) 66-77.

[49] Y. Iwai, Y. Koga, H. Maruyama, Y. Arai, Solubilities of stearic acid, stearyl alcohol, and arachidyl alcohol in supercritical carbon dioxide at $35^{\circ} \mathrm{C}$, J. Chemical and Engineering Data 38 (1993) 506-508.

[50] R.T. Morrison, R.N. Boyd, Organic Chemistry, 6th ed., Prentice Hall, New Jersey, 1992, pp. 732-735.
[51] M. Turk, D. Bolten, Formation of submicron poorly water-soluble drugs by rapic expansion of supercritical solution (RESS): results for naproxen, J. Supercritica Fluids 55 (2010) 778-785.

[52] V. Berbenni, A. Marini, G. Bruni, A. Cardini, Thermo analytical and spectroscopic characterization of solid-state retinoic acid, International J. Pharmaceutics 221 (2001) 123-141. 